\section{Residents Benefit From Insights Into the Role and Challenges of Psychiatry Departments}

To the Editor: We would like that thank the authors of the articles in the March issue of Academic Psychiatry, which focused on the functioning and roles of academic psychiatry departments. As a group of psychiatry residents, comprising interns, education committee representatives, and upcoming chief residents, we benefited immensely from the insights into departmental functioning that were discussed in this issue.

As residents in a program with an interim chairman and with changes to our residency leadership structure, the authors found the discussions regarding succession-planning and the role of interim chairmen to be particularly informative. The article by Magen et al., "Funding the Educational Mission: Challenges to Departments of Psychiatry" has really helped to broaden our understanding of both the financial challenges and wide-ranging mission that an academic department of psychiatry faces. We be- lieve that having better-informed residents, who are aware of these challenges, but also watchful for opportunities, may allow more constructive and fruitful resident involvement in departmental roles such as education and research. Certainly the authors feel better educated to participate in discussions within the program, such as our monthly residency-education committee meeting. The authors encourage residency programs and departments to keep residents informed and to be active participants in departmental roles.

Thank you,

Arshya Vahabzadeh, M.D.

Rachel Goldberg, M.D.

Justine Wittenauer, M.D.

Patricio Riva Posse, M.D.

Sarah Juul, M.D.

Dept. of Psychiatry and Behavioral Sciences

Emory University

Atlanta, GA 